\title{
PROSTATIC HYPERPLASIA;
}

\section{TRANSURETHRAL ELECTRO VAPORIZATION: OUR EXPERIENCE .}

\section{DR. MASUD MALIK}

Assistant Professor Urology

Ayoub Medical College \& Teaching Hospital, Abbotabad

\section{DR. NISAR AHMED}

District Urologist

Civil Hospital Dadu

\section{DR. MOHAMMAD RAZA}

Associate Professor

Ayoub Medical College \& Teaching Hospital, Abbotabad

\author{
Dr. Zahid lqbal \\ Professor of Urology \\ Allied Hospital, Faisalabad \\ Dr. Abdul Manan \\ Associate Professor \\ Services Hospital, Lahore
}

\section{Prof. Mohammad Nawaz Chugtai}

Professor of Urology

Mayo Hospital Lahore

\section{Article Citation:}

Malik M, Ahmed N, Raza M, Iqbal Z, Manan A, Chugtai MN. Prostatic hyperplasia; Transurethral electro vaporization: our experience. Professional Med J Mar 2010;17(1):31-34.

ABSTRACT... Aims and objects. To asses the efficacy, safety and complication of TUEVP on the basis of subjective and objective parameters and to establish an alternative procedure in our setup. Material and Methods: The study was conducted at Urology Department Services Hospital Lahore over a period of four years (1996-2000). A total 50 patients suffering from Bladder outflow symptoms due to BPH were selected for the study. The TUEVP done by standard technique. Results: The mean age was 64.16 with standard deviation of 7.86 years. The mean operating time in TUEVP was 20.6. Mean volume of irrigating fluid during the procedure was 8.28. Few patients require blood transfusion could be shorter resection time and less bleeding during TUEVP. Mean preoperative serum sodium was $138.8 \mathrm{mEq} / 1$. After TUEVP mean changes in serum sodium was $1.1 \mathrm{mEq} / 1$. Post operative mean volume of irrigant used was 11.12 liters. In TUEVP no patients developed significant haemorrhage during first 24 hours. Mean estimated cost of operation was Rs.4160/. Early complication rate like clot retention occurs in $4 \%$ and fever occurs (4\%) while haemorrhage, TURP syndrome, retention of urine and DVT not reported. Late post operative complication included secondary infection( 4\%), Epididymoorchitis (4\%), U.T.I in (12\%), Retrograde ejaculation (24\%) and stricture urethra( $4 \%$ ) patients. The mean symptomatic improvement in IPSS Score was 12.76 after two weeks, 8.72 after three month. Peak flow rate increased $13.4 \mathrm{ml} / \mathrm{s}$ after two weeks and $14.44 \mathrm{ml} / \mathrm{s}$ after three months. Conclusion: TUEVP is the effective and safe procedure with fewer complication and better recovery in our setup but required clinical trials to different urological centers to established its long term efficacy and safety.

Key words: $\quad$ Transurethral Electrovaporization, Benign prostatic hyperplasia complications.

\section{INTRODUCTION}

Benign prostatic hyperplasia is probably the most common condition to afflict the aging men. According to the sir benjmin Brodie the hair becomes grey and scanty the prostate gland usually increase in size ${ }^{1}$. Transurethral electro vaporization which is new method of endoscopic surgery with simple modification of known electrosurgical principles.
The modification is specially designed. Circon ACMI grooved roller electrode (Vapotrode) utilized

$\begin{array}{ll}\text { Article received on: } & 18 / 05 / 2009 \\ \text { Accepted for Publication: } & 27 / 11 / 2009 \\ \text { Received after proof reading: } & 07 / 12 / 2009 \\ \text { Correspondence Address: } & \\ \text { Dr. Nisar Ahmed Shaikh } & \\ \text { District Urologist } & \\ \text { Civil Hospital Dadu Sindh } & \\ \text { drnisarshaikh@yahoo.com } & \end{array}$


transurethrally to vaporize, desiccate and coagulate prostatic tissue ${ }^{2,3}$. This new, minimally invasive technique being used by urologists for surgical ablation of prostate tissues. It is modification of transurethral resection of prostate and involves a sufficiently high electrosurgical current applied through a roll ball electrode to achieve vaporization of prostate tissues ${ }^{4,5}$. Advantage includes familiarly with transurethral route, lack of need of high cost laser equipment and fibers, excellent intra-operative haemostasis, lack of bleeding, or fluid absorption and ability to achieve a TUR like prostate defect at the end of procedure. Transurethral electro vaporization is as effective as standard TURP in the treatment of moderate sized BPH. It also has reduced duration of catheterization, hospitalization, and easier training for the surgeon $^{6,7}$.

\section{MATERIAL AND METHODS}

The study was conducted at Urology Department Services Hospital Lahore over a period of four year( 1996-2000). A total 50 patients suffering from Bladder outflow symptoms due to BPH were selected for the study. Patients having Bleeding disorder, diabetes mellitus, cardiac failure, neurological disorders, renal function impairment, liver disorder, vesical calculi, prostate carcinoma and prostate larger than $50 \mathrm{gm}$ were excluded from the study. A detailed history was taken and thorough examination performed. All patients investigated fully like Urine, Blood CP, ESR, Serum Electrolyte, Serum creatinine, Blood Sugar, Clotting Time, Bleeding Time, Ultrasonography, Plain X Ray KUB, ECG and pre and post operative Serum sodium were carried out. Spinal Anesthesia was used. Prophylactic antibiotic was administered at the time of induction. The TUEVP initially done at the bladder neck at 6 O' clock. Subsequently all tissue between 5 O' clock and 7 O' clock at the bladder neck was vaporized. Median lobe if present were vaporized in a similar way by creating successive furrows starting proximally and ending at the prostatic fossa. The bladder neck was vaporized between 5 O' clock and 7 O' clock position, and passes were repeated until circular bladder fibers were visible. The prostate distal to bladder neck was vaporized next. Repeated furrows were made from 5 o'clock to 1 o'clock and 7 o'clock to 11 o'clock to achieve complete ablation of the entire adenoma of both lobes. Apical tissue can be vaporized last by ante grade and retrograde movement of electrode. $5 \%$ Dextrose water was used for irrigation purpose. Pre-operatively, pulse and BP record was made after every 15 minutes. $22 \mathrm{Fr}$ three-way Foley catheter was inserted after surgery. $0.9 \%$ saline was used for postoperative bladder irrigation and catheter removed after 72 hours.

\section{RESULTS}

The mean age was 64.16 with standard deviation of 7.86 years. The mean operating time in TUEVP was 20.6minutes. Mean volume of irrigating fluid during the procedure was 8.28 .

Few patients required blood transfusion. Mean preoperative serum sodium was $138.8 \mathrm{mEq} / 1$. After TUEVP mean changes in serum sodium was $1.1 \mathrm{mEq} / 1$. Post operative mean volume of irrigant used was 11.12 liters. In TUEVP no patients developed significant haemorrhage during first 24 hours. Mean estimated cost of operation was Rs.4160/. (Table-I).

Table-I. Per \& Post Operative Parameters of TUEVP

Per-Operative Parameters of TUEVP

\begin{tabular}{|l|c|}
\hline Variable & Mean \pm SD \\
\hline 1. Operative Time & $20.6 \pm 9.5$ \\
\hline 2. Volume of Irrigant (Liters) & $8.28 \pm 3.88$ \\
\hline 3. Pre-operative Serum Sodium (mEq/L) & $138.8 \pm 3.48$ \\
\hline Post- Operative Parameters of TUEVP \\
\hline Variables & Mean \pm SD \\
\hline 1. Volume of Irrigant (Liters) & $11.12 \pm 5.36$ \\
\hline 2. Duration of Irrigation (Hours) & $9.48 \pm 2.84$ \\
\hline 3. Cost of Operation (PKR) & $4160 \pm 732$ \\
\hline 4. Hospital Stay (Days) & $4.4 \pm 0.91$ \\
\hline
\end{tabular}

Early complication rate like clot retention occurred (4\%) and fever (4\%) while haemorrhage, TURP syndrome , retention of urine and DVT was not reported. Late post 
operative complication included secondary infection (4\%). Epididymoorchitis (4\%), U.T.I (12\%), Retrograde ejaculation (24\%) and stricture urethra (4\%). The mean symptomatic improvement in IPSS Score 12.76 after two weeks and, 8.72 after three months. (Fig No.1). Peak flow rate increased $13.4 \mathrm{ml} / \mathrm{s}$ after two weeks and 14.44 $\mathrm{ml} / \mathrm{s}$ after three months. (Fig No.2).

Fig-1. Mean symptom IPSS score improvement after TUEVP

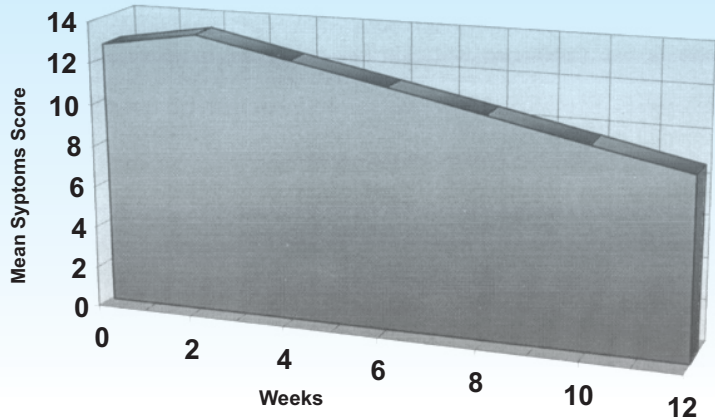

Fig-2. Mean peak flow rate increased after TUEVP 16

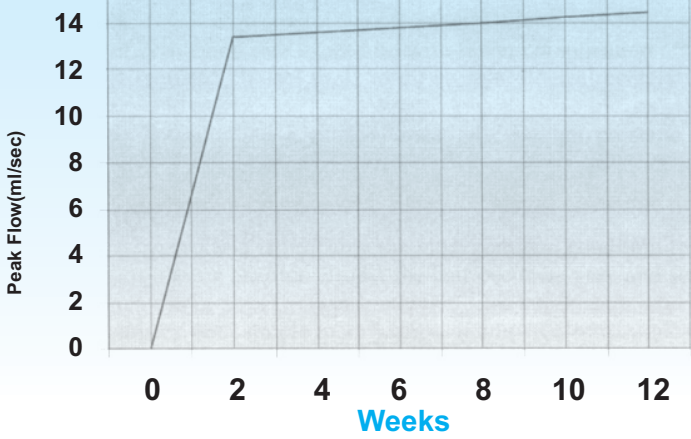

\section{DISCUSSION}

TUEVP is a new endoscopic mode of management for benign prostatic hyperplasia. This modality has been the focus of interest for the last five years. The new electrode is some what similar to roller ball electrode but differs in having grooves on its surface and is gold plated ${ }^{1,2}$. The mean age was 64.16 with standard deviation of 7.86 years which is comparable to other studies ${ }^{1,3}$.The mean operating time in TUEVP was 20.6 minutes which was due to less bleeding during TUEVP and so minimum time was consumed on coagulation. Miles conducted study on TUEVP and found mean operating time was 25 minutes which is comparable to our study ${ }^{8}$. Mean volume of irrigating fluid during the procedure was 8.28 which was comparable to other studies ${ }^{2,3}$. Few patients required blood transfusion which is comparable to other studies ${ }^{4,9}$. During resection absorption of excessive amounts of irrigating fluids in the circulation through open venous channels or extravasated fluid may lead to hypervolumia and dilutional hyponatraemia with clinical features of TURP Syndrome. In our study mean preoperative serum sodium was $138.8 \mathrm{mEq} / 1$. After TUEVP mean changes in serum sodium was $1.1 \mathrm{mEq} / 1$ which are comparable to Narayan and Narysn which reported minimal changes in electrolyte after TUEVP ${ }^{5,6}$. Post operative mean volume of irrigant used was 8.28 liters and mean period of post operative irrigation was 9.84 hours which is due to less post operative bleeding and they required bladder irrigation for shorter duration which is comparable to Stewart $^{7}$ and Zhongua ${ }^{10}$. In TUEVP no patients developed significant haemorrhage during first 24 hours. Benjamin reported one case of early post operative bleeding after TUEVP which is comparable to our study'. Cost is major factor as the patients coming to teaching hospitals belongs to the poor socioeconomics group. Mean estimated cost of operation was Rs.4160/ which is due to reduced volume of irrigating fluid and shorter hospital stay. Early complication rate like clot retention occurs in $4 \%$ and fever occurred in $4 \%$ while haemorrhage, TURP syndrome, retention of urine and DVT was not seen. Late post operative complications included secondary infection (4\%), Epididymoorchitis (4\%), U.T.I (12\%), Retrograde ejaculation (24\%) and stricture urethra $(4 \%)$ comparable to Kaplan and Ekengran studies 2,9 . The mean symptomatic improvement in IPSS Score was 12.76 after two weeks, 8.72 after three month which is comparable to $\mathrm{Hahn}^{3}$ and Miles. Peak flow rate increased $13.4 \mathrm{ml} / \mathrm{s}$ after two weeks and $14.44 \mathrm{ml} / \mathrm{s}$ after three month which is also comparable to studies of Kaplan ${ }^{9}$, Hammadeh ${ }^{4}$ and Gnanaraj ${ }^{11}$.

\section{CONCLUSION}

TUEVP is the effective and safe procedure with fewer complication and better recovery in our setup but 
required clinical trials at different urological centers to established its long term efficacy and safety.

Copyright @ 27 Nov, 2009.

\section{REFERENCES}

1. Benjamin et al. Transurethral electrovaporization of prostate. 18 months follow up. American urological association. Annual convention 1996.

2. Ekengren J. Hohn RG. Complication during transurethral vaporization of the prostate. Urology 1996.48;424-27.

3. Hahn RG. Irrigating fluids in endoscopic surgery. Journal of urology 1997;79:669-80.

4. Hammadeh MY, Fowlis G, Singh M, Philip T. One year follow up of a prospective randomized trial of electro vaporization vs resection of the benign prostate. British journal of urology 1997;79:-l-4.

5. Narayan P, Tewer A, Grokker B, Mustafa S. Factors affecting size and configuration of electrovaporization lesions in the prostate: Urology 1996;47:505-10.

6. Narysn P, Tewar A, Garzotto M, Jones T. Transurethral vapotrode electrvaporization of the prostate. Physical principles, technique and results. Urology 1996;47:50510.

7. Stewart SC, Benjamin D et al. Electrovaporization of the prostate. New technique for the treatment of symptomatic benign hyperplasia. $J$ Endourol 1995;9:413-16

8. Miles BJ, Sils L. Transurethral electrovaporization of the prostate: Text book of benign prostatic hyperplasia. 1996; 463-72.

9. Kaplan A et al. Electrovaporization of the prostate for symptomatic benign prostatic hyperplasia. The one year experience. Proceeding of American urological Association1996:155-200.

10. Zhonghua Nan Ke Xue. Perioperative treatment of senile benign prostatic hyperplasia patients undergoing transurethral electrovaporization of prostate. 2008 Oct; 14(10):920-2.

11. Gnanaraj J, Gnanaraj L. Transurethral electrovaporization of the prostate. ANZ J Surg. 2007 Aug;77(8):708.

\section{The only ljunitations you will ever have are the ones you put on yourselfi. Kristinna Habashy}

